\title{
Methamphetamine Facilitates HIV Infection of Human Monocytes Through Inhibiting Cellular Viral Restriction Factors
}

Yu Liu

Temple University School of Medicine: Lewis Katz School of Medicine at Temple University Fengzhen Meng

Temple University School of Medicine: Lewis Katz School of Medicine at Temple University

xu wang

Temple University School of Medicine: Lewis Katz School of Medicine at Temple University

Jinbiao Liu

Temple University School of Medicine: Lewis Katz School of Medicine at Temple University

Peng Wang

Temple University School of Medicine: Lewis Katz School of Medicine at Temple University

Wenhui Hu

Temple University School of Medicine: Lewis Katz School of Medicine at Temple University

Wenzhe Ho ( $\nabla$ wenzheho@temple.edu )

Temple University https://orcid.org/0000-0002-5235-0606

\section{Research Article}

Keywords: Methamphetamine, human immunodeficiency virus, interferon-stimulated genes, and monocytes

Posted Date: June 7th, 2021

DOl: https://doi.org/10.21203/rs.3.rs-487867/v1

License: (1) (i) This work is licensed under a Creative Commons Attribution 4.0 International License. Read Full License 


\section{Abstract \\ Background}

Methamphetamine (METH), a potent addictive psychostimulant, is highly prevalent in HIV-infected individuals. Clinically, METH use is implicated in alteration of immune system and increase of HIV spread/replication. Therefore, it is of importance to examine whether METH has direct effect on HIV infection of monocytes, the major target and reservoir cells for the virus.

\section{Result}

METH-treated monocytes were more susceptible to HIV infection as evidenced by increased levels of viral p24 protein and expression of viral GAG gene. Mechanistically, METH treatment of monocytes inhibited the expression of the antiviral IFN-stimulated genes (ISGs: OAS2, GBP5, ISG56, Viperin and ISG15) and the HIV restriction microRNAs. In addition, METH treatment of monocytes significantly decreased STAT1 expression at both mRNA and protein levels.

\section{Conclusions}

These findings suggest a previously unrecognized mechanism for HIV persistent infection in the primary target and reservoir cells.

\section{Introduction}

METH is one of the most widely abused illicit drugs among HIV-infected individuals. METH use and HIV infection frequently coexist due to the association of METH use with engagement of high-risk behaviors [1-3]. There is a high prevalence of HIV infection in METH using population [4,5]. Among men who have sex with men, those who use METH are more susceptible to HIV infection than non-users [6-10]. Clinically, METH use has been implicated in HIV disease progression [11]. Active METH users with HIV infection display higher levels of viral load than non-users [12]. In addition, METH users have delayed viral suppression after initiation of antiretroviral therapy (ART), higher levels of blood HIV RNA, increased frequency of drug resistance mutations and accelerated progression to AIDS [13-17]. METH abuse contributes to $\mathrm{CD}^{+} \mathrm{T}$ cells depletion, inflammation/immune activation, and the promotion of HIV entry and disease progression [18].

Cells of monocyte/macrophage lineage are crucial in initial HIV infection and implicated in the immunopathogenesis of HIV disease. Monocytes are among the first and major cell types infected by HIV and function as reservoirs for the virus. However, unlike tissue macrophages and in vitro monocytederived macrophages which are highly susceptible to HIV infection, peripheral blood monocytes are refractory to HIV infection in vivo and in vitro, and only a small percentage of monocytes harbor the virus 
$[19,20]$. Despite of their resistance to HIV infection, monocytes are involved in HIV infection of the central nervous system (CNS) as they can bring the virus to the brain [21]. A study reported that HIV-infected monocytes are more likely to cross the blood brain barrier (BBB) as compared to uninfected monocytes [22]. Among HIV-infected METH users, HIV-associated neurocognitive disorders (HAND) are the more frequent and severe $[23,24]$. A recent study demonstrated that METH could enhance HIV infection of neural progenitor cells, a possible mechanism for the impairment or disruption of neurocognitive functioning in HIV-infected individuals with NeuroAIDS [25]. Several studies showed that elevated extracellular CNS dopamine by METH abuse could facilitate uninfected and HIV-infected CD $14^{+} \mathrm{CD} 16^{+}$ monocytes transmigration across the BBB, resulting in the propagation of viral reservoirs and inflammation in the CNS which contribute to the development of HAND $[26,27]$. Thus, it is of a great interest to determine the impact of METH on susceptibility of peripheral blood monocytes to HIV infection. In addition, it is critical to understand the pathological effects of METH on the specific intracellular innate immunity against HIV in monocytes.

\section{Results}

\section{METH enhances HIV infection}

We first examined cytotoxicity effect of METH on monocytes. As shown in Supplemental Fig. 1, METH at the concentration as high as 1000um had little effect on cell viability. We then studied whether METH could enhance susceptibility of monocytes to HIV infection. As demonstrated in Figs. 1A and 1B, METH treatment of monocytes significantly increased the expression of both intracellular and extracellular HIV GAG gene expression. In addition, METH-treated monocytes showed higher levels of HIV p24 protein than untreated cells (Figs. 1C and 1D). The enhancing effects of METH on HIV GAG gene expression and p24 protein production were dose-dependent (Figs. 1A-1D).

\section{METH suppresses antiviral ISGs}

We next examined the effect of METH on the expression of the intracellular antiviral ISGs. As shown in Figs. 2A and 2B, METH dose-dependently inhibited the expression of the antiviral ISGs (OAS2, GBP5, ISG56, Viperin, ISG15) at $24 \mathrm{~h}$ post-treatment. In addition, the Western blot analysis demonstrated that METH-treated monocytes had lower protein levels of the antiviral ISGs than the untreated cells (Fig. 2C). To determine whether the inhibitory effect of METH on the ISGs is not associated with cytotoxicity, we treated monocytes with different concentrations of METH for 4 days. We found that METH at the concentration as high as $1000 \mu \mathrm{M}$ had little toxic effect on monocytes (Supplementary Fig 1).

\section{METH inhibits IRF7 and STAT1}

To study the mechanisms of METH-mediated ISGs inhibition, we examined whether the expression of several IFN regulatory factors (IRFs), the key modulators of the IFNs/ISGs signaling pathway, are affected by METH. As shown in Fig. 2D, although METH had little effect on the expression of IRF1, IRF3 and IRF5, METH-treated cells expressed lower levels of IRF7 at both mRNA and protein levels as compared to the 
untreated cells. We also examined whether METH has a negative impact on the expression of STAT family members including STAT1, STAT2 and STAT3, which are crucial in the host innate immunity against viral infection $[28,29]$. As shown in Fig. 2E, while METH treatment of monocytes had little effect on STAT2 and STAT3 expression, it significantly inhibited STAT1 expression at both mRNA and protein levels.

\section{METH inhibits HIV restriction miRNAs}

Our earlier study showed that monocytes contain significantly higher levels of the HIV restriction miRNAs than monocyte-derived macrophages, which explains why monocytes are refractory to HIV infection [30]. We thus investigated whether METH negatively influences the expression of the HIV restriction miRNAs in monocytes. As shown in Fig. 2F, METH treatment of monocytes suppressed the expression of the intracellular HIV restriction miRNAs (mi-28, miR-29 family members, miR-125b, miR-150, miR-223, and miR-382). In addition, we observed that lower levels of these HIV restriction miRNAs in supernatant of monocyte cultures $36 \mathrm{~h}$ after METH treatment than those in untreated cells (Fig. 2G).

\section{Discussion}

Although METH use has been linked to HIV transmission and infection, its pathological effects on the host cell-mediated specific innate immunity against HIV infection remain to be determined. The earlier studies reported that METH could enhance HIV infection of several cell types, including dendritic cells [31], macrophages [32, 33], CD4 ${ }^{+} \mathrm{T}$ cells [34, 35], and neural progenitor cells [25]. However, it is unclear whether METH facilitates HIV infection of primary human monocytes. In the present study, we demonstrated that METH treatment of the monocytes significantly enhanced HIV infection/replication at both intracellular and extracellular levels (Figs. 1A-1D). To investigate the underlying mechanisms of METH-mediated HIV enhancement in monocytes, we examined that the impact of METH on the expression of IFNs and the downstream effectors in IFNs signaling pathway. We found that although METH treatment of monocytes had little effect on IFN- $\alpha$ and IFN- $\beta$ expression (data not shown), it downregulated the expression of the antiviral ISGs, including OAS2, GBP5, ISG56, Viperin, and ISG15 (Figs. 2A2C). These ISGs are known to have the ability to restrict HIV replication at different steps of viral replication cycle [36-40]. For instance, Krapp et al demonstrated that the expression of GBP5 could interfere with the processing and virion incorporation of the HIV envelope glycoprotein, which remarkably reduce virion incorporation of mature gp120 and enhance virion-associated immature gp160 precursor, leading to the inhibition of HIV infectivity [37]. Okumura et al showed that ISG15 impaired the interaction between HIV GAG and tumor susceptibility gene 101 (Tsg101), and suppressed HIV virion release [41].

Given that the IFN signaling pathway is responsible for the production of the antiviral ISGs, we also examined the impact of METH on IFN regulatory factors (IRFs), particularly IRF1, IRF3, IRF5 and IRF7, the key players in regulating the expression of antiviral ISGs and producing an antiviral state [42]. We found that while METH had little effect on IRF1, IRF3, IRF5, it specifically suppressed IRF7 expression in monocytes at both mRNA and protein levels (Fig. 2D). In addition, we observed that METH treatment of 
monocytes inhibited the expression of STAT1, a crucial regulatory factor in IFNs-mediated induction of antiviral ISGs $[43,44]$. The effect of METH on STAT1 appeared to be specific, as it had little effect on the expression of STAT2 and STAT3 (Fig. 2E).

In addition to the HIV restriction factors of protein nature, a cluster of HIV restriction miRNAs have also been revealed to contribute to HIV latency in resting $C D 4^{+} T$ cells $[45,46]$. These cellular miRNAs interact with the $3^{\prime}$-termini of HIV RNA, resulting in the transcriptional inefficiency and post-transcriptional suppression $[47,48]$. We documented that monocytes expression much higher levels of HIV restriction miRNAs (miRNA-382, -223, -150, and - 28) than monocyte-derived macrophages, which may contribute to HIV latency in monocytes [30]. Therefore, it is of interest to determine whether METH use inhibits these HIV restriction miRNAs, which are implicated in HIV latency. Among these cellular miRNAs, the miR-29 family members (miR-29a, miR-29b, and miR-29c) suppress HIV replication by targeting a highly conserved region of HIV [49]. Importantly, our early study documented that the levels of the cellular HIV restriction miRNAs negatively correlated with susceptibility of monocytes and macrophages to HIV infection [30]. We also reported that ART failed to restore the levels of several HIV restriction miRNAs in PBMCs of HIV-infected men who have sex with men who used METH [50]. Therefore, it is clinically relevant to seek the direct evidence of how METH negatively impacts on the HIV restriction miRNAs. Our observation that METH could significantly suppress the expression of the HIV restriction miRNAs (Figs. 2F and 2G) provide not only direct evidence for our in vivo observation [50], but also an additional mechanism for METH-mediated enhancement of HIV infection.

In summary, we demonstrate that METH can enhance HIV infection in monocytes through the inhibition of the multiple cellular antiviral factors (ISGs and miRNAs) at both mRNA and protein levels. Although it is possible that there are additional mechanisms involved in the METH action on HIV, compromising the intracellular immunity that is crucial for control of HIV replication should be responsible for much of METH-mediated HIV enhancement in monocytes. These findings suggest that METH use is a contributing factor for HIV infection and persistence in monocytes. As HIV-infected individuals are living longer with ART and many of infected individuals are METH users, to further identify the pathological role of METH in HIV-infected reservoir cells is necessary for understanding the mechanisms of HIV persistence and developing strategies for the viral eradication.

\section{Conclusions}

These findings suggest a previously unrecognized mechanism for HIV persistent infection in the primary target and reservoir cells.

\section{Materials And Methods}

\section{Cells and reagents}


Purified human peripheral blood monocytes were obtained from Human Immunology Core at the University of Pennsylvania (Philadelphia, PA, USA). The Core has the Institutional Review Board approval for blood collection from healthy donors. Freshly isolated monocytes were cultured in $1640 \mathrm{RPMI}$ medium supplemented with $10 \%$ fetal bovine serum, $1 \%$ nonessential amino acid, $1 \%$ L-glutamine and $1 \%$ penicillin-streptomycin solution. Rabbit antibodies against OAS2, GBP5, ISG56, Viperin, ISG15, IRF7, pIRF7, STAT1, p-STAT1 and GAPDH were purchased from Cell Signaling Technology (Danvers, MA, USA). Mouse anti-HIV p24 antibody was obtained from the NIH AIDS Research and Reference Reagent Program (Bethesda, MD, USA). METH was purchased from Sigma Aldrich (St Louis, MO, USA). METH powder was dissolved in sterile endotoxin-free water (HyPure ${ }^{T M}$ Cell culture grade water, GE Healthcare Life Science, Logan, UT, USA) and stored at $4^{\circ} \mathrm{C}$.

\section{HIV infection and METH Treatment}

HIV Bal strain was obtained from AIDS Reagent Program (NIH, Bethesda, MD. Freshly isolated and purified monocytes in a 48-well plate were treated with METH at clinically relevant concentrations [51-54] $(0,100,150$, and $250 \mu \mathrm{M})$ for $24 \mathrm{~h}$ before being infected with HIV Bal strain ( $\mathrm{p} 2460 \mathrm{ng} / 10^{6}$ cells) overnight. The cells were then washed three times with plain RPMI to remove any unabsorbed virus and cultured in the presence of METH for $72 \mathrm{~h}$.

\section{MTS assay}

The cytotoxic effect of METH on monocytes was evaluated by MTS (3-(4, 5-dimethylthiazol-2-yl)-5(3carboxymethoxyphenyl)-2-(4-sulfophenyl)-2H-tetrazolium, innersalt) assay. Freshly isolated human blood monocytes $\left(2 \times 10^{4}\right.$ cells/well) were placed in 96-well round bottom plates, and treated with different concentrations of $\operatorname{METH}(0,100,150,250,400,600$, and $1000 \mu \mathrm{M})$ for $96 \mathrm{~h}$. The cells were then incubated with CellTiter $96^{\circledR} \mathrm{AQ}_{\text {ueous }}$ One Solution Reagent (Promega Corporation, Madison, WI) containing MTS and phenazine ethosulfate for $4 \mathrm{~h}$ at $37^{\circ} \mathrm{C}$. Absorbance at $490 \mathrm{~nm}$ was measured by a plate reader (SpectraMax i3, Molecular Devices, Sunnyvale, CA, USA).

\section{ELISA and western blot assays}

HIV p24 protein levels in monocyte culture supernatant were determined by HIV p24 ELISA kit from Abnova (Taipei, Taiwan) as instructed by the manufacturer. HIV p24 protein levels in uninfected and infected monocytes were determined by Western blot assay. Briefly, the cell pellets were lysed with RIPA lysis buffer supplemented with protease/phosphatase inhibitors (Sigma Aldrich, St Louis, MO). The protein concentrations were determined by the bicinchoninic acid (BCA) assay (ChemCruz, Dallas, TX). The blots were incubated with primary antibodies in $5 \%$ nonfat milk in PBS overnight at $4{ }^{\circ} \mathrm{C}$, then washed with PBS containing $0.5 \%$ Tween. The blots were further incubated with horseradish peroxidaseconjugated second antibodies at room temperature for an hour, then washed with PBST and visulized by enhanced chemiluminescence (Amersham, Bucks, UK) in a Fuji Film LAS-4000 imaging analyzer (GE Life Sciences, NJ, USA). 


\section{RNA and microRNA extraction and quantification}

Freshly isolated monocytes in 48-well plates were treated with or without METH $(100,150$, and $250 \mu \mathrm{M})$ for different time points $(0,6,12$, and $24 \mathrm{~h})$. Total RNAs were extracted with Tri-reagent (Molecular Research Center, $\mathrm{OH}, \mathrm{USA})$. RNA $(1 \mu \mathrm{g})$ was subjected to reverse transcriptase PCR using reagents from Promega (Promega, WI, USA). The cDNA sample was then subjected to the real-time PCR using iQ SYBR Green Supermix (Bio-Rad Laboratories, CA, USA). All values were normalized to GAPDH mRNA. The sequences of oligonucleotide primers used in this study are listed in Table 1. Extracellular miRNAs were extracted from supernatant of monocyte cultures using the miRNeasy Mini Kit (Qiagen, CA, USA). The miRNAs from cells or supernatant were reversely transcribed with miScript Reverse Transcription Kit (Qiagen, CA, USA). The real-time PCR for the miRNAs quantification was carried out with miScript Primer Assays using miScript SYBR Green PCR Kit from Qiagen as previously described [30].

\section{HIV GAG gene quantification}

HIV GAG gene copy numbers in monocytes or monocytes culture supernatant were determined by the real-time PCR. RNAs from cells or the cell-free supernatant were extracted with Tri-reagent (for tissues, cells cultured in monolayer, or cell pellets) or Tri-reagent (for whole blood, serum/plasma or cell culture supernatant) according to the manufacturer's instructions, respectively. HIV GAG standards with known copy numbers were used to quantify viral GAG gene expression in the culture supernatant.

\section{Statistical analysis}

Data were expressed as mean \pm standard deviation (mean \pm SD) of three experiments using monocytes from three different donors. Statistical significance was measured by Student's t-test using GraphPad Prism Statistical Software (GraphPad Software, La Jolla, USA). ${ }^{\star} P<0.05$ and ${ }^{*} P<0.01$ indicate statistic difference between compared groups.

\section{Declarations}

\section{Author Contributions}

$Y L, F Z M, X W, W Z H$ designed the research; $Y L, F Z M, P W, J B L$, and $W H H$ performed the experiments and analyzed the data; $Y L, F Z M, X W$, and $W Z H$ interpreted the data and wrote the paper; $Y L, F Z M, X W, J B L$, WHH, WZH discussed and edited the paper.

\section{Acknowledgements}

Not applicable

\section{Funding}

This work is financially supported by the NIH (DA 51396 and DA45568 for WZ Ho). 


\section{Ethics approval and consent to participate}

Not applicable.

\section{Consent for publication}

All authors agree to publish this paper.

\section{Competing interests}

No potential conflict of interest was reported by the authors.

\section{Data availability}

The datasets used and/or analyzed during the current study are available from the corresponding author on reasonable request.

\section{References}

1. Marshall BD, Wood E, Shoveller JA, Patterson TL, Montaner JS, Kerr T: Pathways to HIV risk and vulnerability among lesbian, gay, bisexual, and transgendered methamphetamine users: a multicohort gender-based analysis. BMC Public Health 2011, 11:20.

2. Pitpitan EV, Semple SJ, Zians J, Strathdee SA, Patterson TL: Mood, Meth, Condom Use, and Gender: Latent Growth Curve Modeling Results from a Randomized Trial. AIDS Behav 2018.

3. Semple SJ, Patterson TL, Grant I: Motivations associated with methamphetamine use among HIV+ men who have sex with men. J Subst Abuse Treat 2002, 22:149-156.

4. Nerlander LMC, Hoots BE, Bradley H, Broz D, Thorson A, Paz-Bailey G, Group N: HIV infection among MSM who inject methamphetamine in 8 US cities. Drug Alcohol Depend 2018, 190:216-223.

5. Vu NT, Maher L, Zablotska I: Amphetamine-type stimulants and HIV infection among men who have sex with men: implications on HIV research and prevention from a systematic review and metaanalysis. Journal of the International AIDS Society 2015, 18:19273.

6. Morin SF, Steward WT, Charlebois ED, Remien RH, Pinkerton SD, Johnson MO, Rotheram-Borus MJ, Lightfoot M, Goldstein RB, Kittel L et al: Predicting HIV transmission risk among HIV-infected men who have sex with men: findings from the healthy living project. J Acquir Immune Defic Syndr 2005, 40:226-235.

7. Plankey MW, Ostrow DG, Stall R, Cox C, Li X, Peck JA, Jacobson LP: The relationship between methamphetamine and popper use and risk of HIV seroconversion in the multicenter AIDS cohort study. J Acquir Immune Defic Syndr 2007, 45:85-92.

8. Shoptaw S, Reback CJ: Associations between methamphetamine use and HIV among men who have sex with men: a model for guiding public policy. J Urban Health 2006, 83:1151-1157. 
9. Shoptaw S, Reback CJ: Methamphetamine use and infectious disease-related behaviors in men who have sex with men: implications for interventions. Addiction 2007, 102 Suppl 1:130-135.

10. Urbina A, Jones K: Crystal methamphetamine, its analogues, and HIV infection: medical and psychiatric aspects of a new epidemic. Clinical infectious diseases : an official publication of the Infectious Diseases Society of America 2004, 38:890-894.

11. Moore RD, Keruly JC, Chaisson RE: Differences in HIV disease progression by injecting drug use in HIV-infected persons in care. J Acquir Immune Defic Syndr 2004, 35:46-51.

12. Ellis RJ, Childers ME, Cherner M, Lazzaretto D, Letendre S, Grant I, Group HIVNRC: Increased human immunodeficiency virus loads in active methamphetamine users are explained by reduced effectiveness of antiretroviral therapy. The Journal of infectious diseases 2003, 188:1820-1826.

13. Carrico AW, Johnson MO, Colfax GN, Moskowitz JT: Affective correlates of stimulant use and adherence to anti-retroviral therapy among HIV-positive methamphetamine users. AIDS Behav 2010, 14:769-777.

14. Colfax GN, Vittinghoff E, Grant R, Lum P, Spotts G, Hecht FM: Frequent methamphetamine use is associated with primary non-nucleoside reverse transcriptase inhibitor resistance. Aids 2007, 21:239241.

15. Fairbairn N, Kerr T, Milloy MJ, Zhang R, Montaner J, Wood E: Crystal methamphetamine injection predicts slower HIV RNA suppression among injection drug users. Addict Behav 2011, 36:762-763.

16. Kapadia F, Cook JA, Cohen MH, Sohler N, Kovacs A, Greenblatt RM, Choudhary I, Vlahov D: The relationship between non-injection drug use behaviors on progression to AIDS and death in a cohort of HIV seropositive women in the era of highly active antiretroviral therapy use. Addiction 2005, 100:990-1002.

17. Massanella M, Gianella S, Schrier R, Dan JM, Perez-Santiago J, Oliveira MF, Richman DD, Little SJ, Benson CA, Daar ES et al: Methamphetamine Use in HIV-infected Individuals Affects T-cell Function and Viral Outcome during Suppressive Antiretroviral Therapy. Scientific reports 2015, 5:13179.

18. Jiang J, Wang M, Liang B, Shi Y, Su Q, Chen H, Huang J, Su J, Pan P, Li Y et al: In vivo effects of methamphetamine on HIV-1 replication: A population-based study. Drug Alcohol Depend 2016, 159:246-254.

19. Kedzierska K, Crowe SM: The role of monocytes and macrophages in the pathogenesis of HIV-1 infection. Current medicinal chemistry 2002, 9:1893-1903.

20. Zhu T: HIV-1 in peripheral blood monocytes: an underrated viral source. J Antimicrob Chemother 2002, 50:309-311.

21. Strazza M, Pirrone V, Wigdahl B, Nonnemacher MR: Breaking down the barrier: the effects of HIV-1 on the blood-brain barrier. Brain research 2011, 1399:96-115.

22. Williams DW, Eugenin EA, Calderon TM, Berman JW: Monocyte maturation, HIV susceptibility, and transmigration across the blood brain barrier are critical in HIV neuropathogenesis. J Leukoc Biol 2012, 91:401-415. 
23. Sanmarti M, Ibanez L, Huertas S, Badenes D, Dalmau D, Slevin M, Krupinski J, Popa-Wagner A, Jaen A: HIV-associated neurocognitive disorders. J Mol Psychiatry 2014, 2:2.

24. Zayyad Z, Spudich S: Neuropathogenesis of HIV: from initial neuroinvasion to HIV-associated neurocognitive disorder (HAND). Curr HIV/AIDS Rep 2015, 12:16-24.

25. Skowronska M, McDonald M, Velichkovska M, Leda AR, Park M, Toborek M: Methamphetamine increases HIV infectivity in neural progenitor cells. J Biol Chem 2018, 293:296-311.

26. Calderon TM, Williams DW, Lopez L, Eugenin EA, Cheney L, Gaskill PJ, Veenstra M, Anastos K, Morgello S, Berman JW: Dopamine Increases CD14(+)CD16(+) Monocyte Transmigration across the Blood Brain Barrier: Implications for Substance Abuse and HIV Neuropathogenesis. J Neuroimmune Pharmacol 2017, 12:353-370.

27. Gaskill PJ, Calderon TM, Coley JS, Berman JW: Drug induced increases in CNS dopamine alter monocyte, macrophage and T cell functions: implications for HAND. J Neuroimmune Pharmacol 2013, 8:621-642.

28. Chen K, Liu J, Cao X: Regulation of type I interferon signaling in immunity and inflammation: A comprehensive review. J Autoimmun 2017, 83:1-11.

29. Hillmer EJ, Zhang H, Li HS, Watowich SS: STAT3 signaling in immunity. Cytokine Growth Factor Rev 2016, 31:1-15.

30. Wang X, Ye L, Hou W, Zhou Y, Wang YJ, Metzger DS, Ho WZ: Cellular microRNA expression correlates with susceptibility of monocytes/macrophages to HIV-1 infection. Blood 2009, 113:671-674.

31. Nair MP, Saiyed ZM, Nair N, Gandhi NH, Rodriguez JW, Boukli N, Provencio-Vasquez E, Malow RM, Miguez-Burbano MJ: Methamphetamine enhances HIV-1 infectivity in monocyte derived dendritic cells. J Neuroimmune Pharmacol 2009, 4:129-139.

32. Liang $H$, Wang $X$, Chen $H$, Song L, Ye L, Wang SH, Wang YJ, Zhou L, Ho WZ: Methamphetamine enhances HIV infection of macrophages. Am J Pathol 2008, 172:1617-1624.

33. Wang X, Wang Y, Ye L, Li J, Zhou Y, Sakarcan S, Ho W: Modulation of intracellular restriction factors contributes to methamphetamine-mediated enhancement of acquired immune deficiency syndrome virus infection of macrophages. Curr HIV Res 2012, 10:407-414.

34. Lawson KS, Prasad A, Groopman JE: Methamphetamine Enhances HIV-1 Replication in CD4(+) TCells via a Novel IL-1beta Auto-Regulatory Loop. Frontiers in immunology 2020, 11:136.

35. Prasad A, Kulkarni R, Shrivastava A, Jiang S, Lawson K, Groopman JE: Methamphetamine functions as a novel CD4(+) T-cell activator via the sigma-1 receptor to enhance HIV-1 infection. Scientific reports $2019,9: 958$.

36. Fagone P, Nunnari G, Lazzara F, Longo A, Cambria D, Distefano G, Palumbo M, Nicoletti F, Malaguarnera L, Di Rosa M: Induction of OAS gene family in HIV monocyte infected patients with high and low viral load. Antiviral research 2016, 131:66-73.

37. Krapp C, Hotter D, Gawanbacht A, McLaren PJ, Kluge SF, Sturzel CM, Mack K, Reith E, Engelhart S, Ciuffi A et al: Guanylate Binding Protein (GBP) 5 Is an Interferon-Inducible Inhibitor of HIV-1 Infectivity. Cell Host Microbe 2016, 19:504-514. 
38. Morales DJ, Lenschow DJ: The antiviral activities of ISG15. J Mol Biol 2013, 425:4995-5008.

39. Nasr N, Alshehri AA, Wright TK, Shahid M, Heiner BM, Harman AN, Botting RA, Helbig KJ, Beard MR, Suzuki K et al: Mechanism of Interferon-Stimulated Gene Induction in HIV-1-Infected Macrophages. Journal of virology 2017, 91.

40. Nasr N, Maddocks S, Turville SG, Harman AN, Woolger N, Helbig KJ, Wilkinson J, Bye CR, Wright TK, Rambukwelle $D$ et al: HIV-1 infection of human macrophages directly induces viperin which inhibits viral production. Blood 2012, 120:778-788.

41. Okumura A, Lu G, Pitha-Rowe I, Pitha PM: Innate antiviral response targets HIV-1 release by the induction of ubiquitin-like protein ISG15. Proceedings of the National Academy of Sciences of the United States of America 2006, 103:1440-1445.

42. Ikushima $\mathrm{H}$, Negishi $\mathrm{H}$, Taniguchi T: The IRF family transcription factors at the interface of innate and adaptive immune responses. Cold Spring Harb Symp Quant Biol 2013, 78:105-116.

43. Brierley MM, Fish EN: Stats: multifaceted regulators of transcription. J Interferon Cytokine Res 2005, 25:733-744.

44. Raftery N, Stevenson NJ: Advances in anti-viral immune defence: revealing the importance of the IFN JAK/STAT pathway. Cell Mol Life Sci 2017, 74:2525-2535.

45. Huang J, Wang F, Argyris E, Chen K, Liang Z, Tian H, Huang W, Squires K, Verlinghieri G, Zhang H: Cellular microRNAs contribute to HIV-1 latency in resting primary CD4+ T lymphocytes. Nat Med 2007, 13:1241-1247.

46. Pilakka-Kanthikeel S, Nair MP: Interaction of drugs of abuse and microRNA with HIV: a brief review. Front Microbio/ 2015, 6:967.

47. Swaminathan G, Navas-Martin S, Martin-Garcia J: MicroRNAs and HIV-1 infection: antiviral activities and beyond. J Mol Biol 2014, 426:1178-1197.

48. Whisnant AW, Bogerd HP, Flores O, Ho P, Powers JG, Sharova N, Stevenson M, Chen CH, Cullen BR: Indepth analysis of the interaction of HIV-1 with cellular microRNA biogenesis and effector mechanisms. mBio 2013, 4:e000193.

49. Nathans R, Chu CY, Serquina AK, Lu CC, Cao H, Rana TM: Cellular microRNA and P bodies modulate host-HIV-1 interactions. Mol Cell 2009, 34:696-709.

50. Liu MQ, Zhao M, Kong WH, Peng JS, Wang F, Qiu HY, Zhu ZR, Tang L, Sang M, Wu JG et al: Antiretroviral Therapy Fails to Restore Levels of HIV-1 Restriction miRNAs in PBMCs of HIV-1-infected MSM. Medicine (Baltimore) 2015, 94:e2116.

51. Kalasinsky KS, Bosy TZ, Schmunk GA, Reiber G, Anthony RM, Furukawa Y, Guttman M, Kish SJ: Regional distribution of methamphetamine in autopsied brain of chronic human methamphetamine users. Forensic Sci Int 2001, 116:163-169.

52. Klette KL, Kettle AR, Jamerson MH: Prevalence of use study for amphetamine (AMP), methamphetamine (MAMP), 3,4-methylenedioxy-amphetamine (MDA), 3,4-methylenedioxymethamphetamine (MDMA), and 3,4-methylenedioxy-ethylamphetamine (MDEA) in military entrance processing stations (MEPS) specimens. J Anal Toxicol 2006, 30:319-322. 
53. Schepers RJ, Oyler JM, Joseph RE, Jr., Cone EJ, Moolchan ET, Huestis MA: Methamphetamine and amphetamine pharmacokinetics in oral fluid and plasma after controlled oral methamphetamine administration to human volunteers. Clin Chem 2003, 49:121-132.

54. Takayasu T, Ohshima T, Nishigami J, Kondo T, Nagano T: Screening and determination of methamphetamine and amphetamine in the blood, urine and stomach contents in emergency medical care and autopsy cases. J Clin Forensic Med 1995, 2:25-33.

\section{Tables}


Table 1

Primers Pairs

\begin{tabular}{|c|c|c|}
\hline Gene & Orientation & Sequence $\left(5^{\prime}-3^{\prime}\right)$ \\
\hline \multirow[t]{2}{*}{ GAPDH } & Forward & GGTGGTCTCCTCTGACTTCAACA \\
\hline & Reverse & GTTGCTGTAGCCAAATTCGTTGT \\
\hline \multirow[t]{2}{*}{ HIV GAG } & Forward & ATAATCCACCTATCCCAGTAGGAGAAA \\
\hline & Reverse & TTTGGTCCTTGTCTTATGTCCAGAATGC \\
\hline \multirow[t]{2}{*}{ OAS2 } & Forward & CAGTCCTGGTGAGTTTGCAGT \\
\hline & Reverse & ACAGCGAGGGTAAATCCTTGA \\
\hline \multirow[t]{2}{*}{ GBP5 } & Forward & CAGGAACAACAGATGCAGGA \\
\hline & Reverse & TCATCGTTATTAACAGTCCTCTGG \\
\hline \multirow[t]{2}{*}{ ISG56 } & Forward & TTCGGAGAAAGGCATTAGA \\
\hline & Reverse & TCCAGGGCTTCATTCATAT \\
\hline \multirow[t]{2}{*}{ Viperin } & Forward & TGGGTGCTTACACCTGCTG \\
\hline & Reverse & TGAAGTGATAGTTGACGCTGGT \\
\hline \multirow[t]{3}{*}{ ISG15 } & Forward & GGCTGGGAGCTGACGGTGAAG \\
\hline & Reverse & GCTCCGCCCGCCAGGCTCTGT \\
\hline & Reverse & TCAGTCTTGGTTTCAACGTGGT \\
\hline \multirow[t]{2}{*}{ IRF1 } & Forward & TGAAGCTACAACAGATGAGG \\
\hline & Reverse & AGTAGGTACCCCTTCCCATC \\
\hline \multirow[t]{2}{*}{ IRF3 } & Forward & ACCAGCCGTGGACCAAGAG \\
\hline & Reverse & TACCAAGGCCCTGAGGCAC \\
\hline \multirow[t]{2}{*}{ IRF5 } & Forward & AAGCCGATCCGGCCAA \\
\hline & Reverse & GGAAGTCCCGGCTCTTGTTAA \\
\hline \multirow[t]{2}{*}{ IRF7 } & Forward & TGGTCCTGGTGAAGCTGGAA \\
\hline & Reverse & GATGTCGTCATAGAGGCTGTTGG \\
\hline \multirow[t]{2}{*}{ STAT1 } & Forward & CCGTGGCACTGCATACAATC \\
\hline & Reverse & ACCATGCCGAATTCCCAAAG \\
\hline \multirow[t]{2}{*}{ STAT2 } & Forward & CCCCATCGACCCСТCATC \\
\hline & Reverse & GAGTCTCACCAGCAGCCTTGT \\
\hline
\end{tabular}




\begin{tabular}{|lll|}
\hline Gene & Orientation & Sequence $\left(\mathbf{5}^{\prime} \mathbf{3}^{\prime} \mathbf{3}^{\prime}\right.$ \\
\hline STAT3 & Forward & CTGCCCCATACCTGAAGACC \\
\cline { 2 - 3 } & Reverse & TCCTCACATGGGGGAGGTAG \\
\hline
\end{tabular}

Figures

A

Intracellular

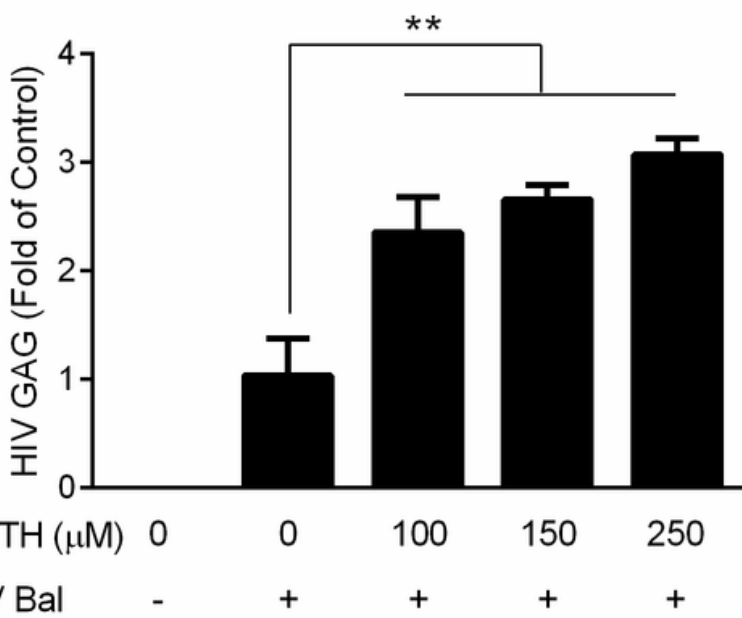

C

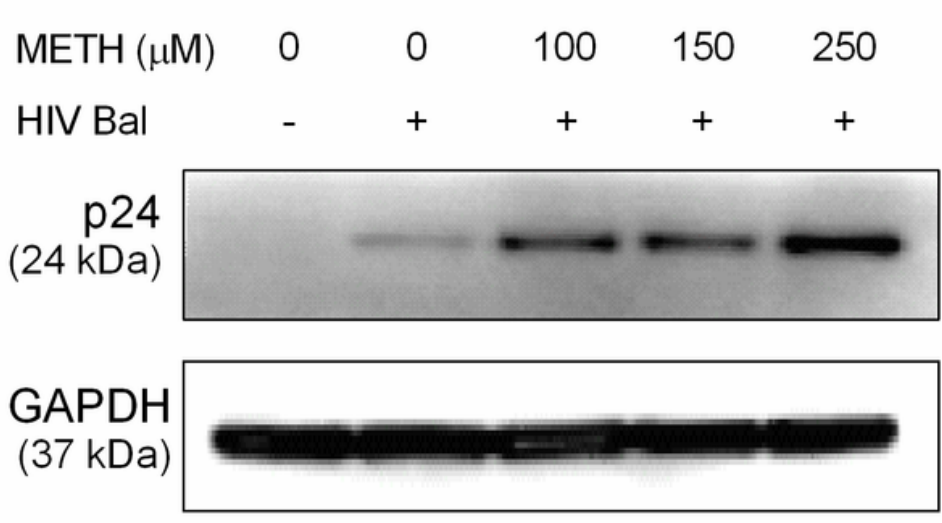

B

Extracellular

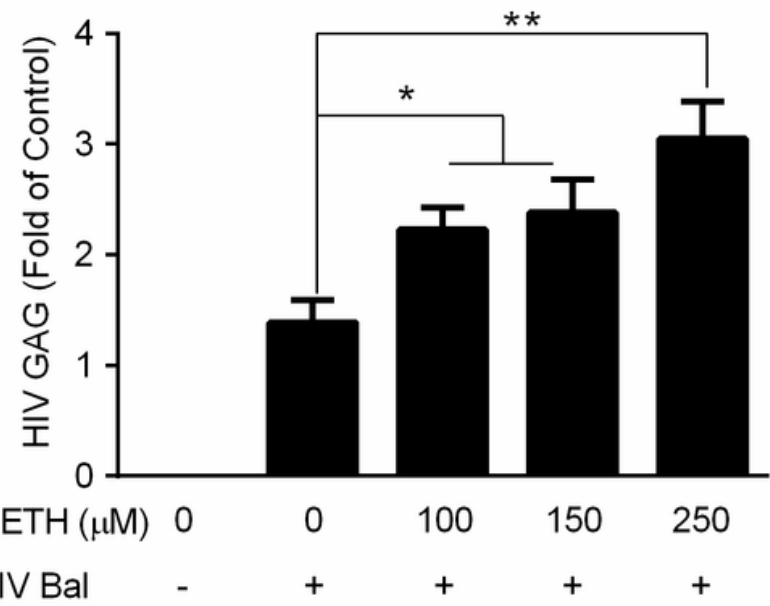

D

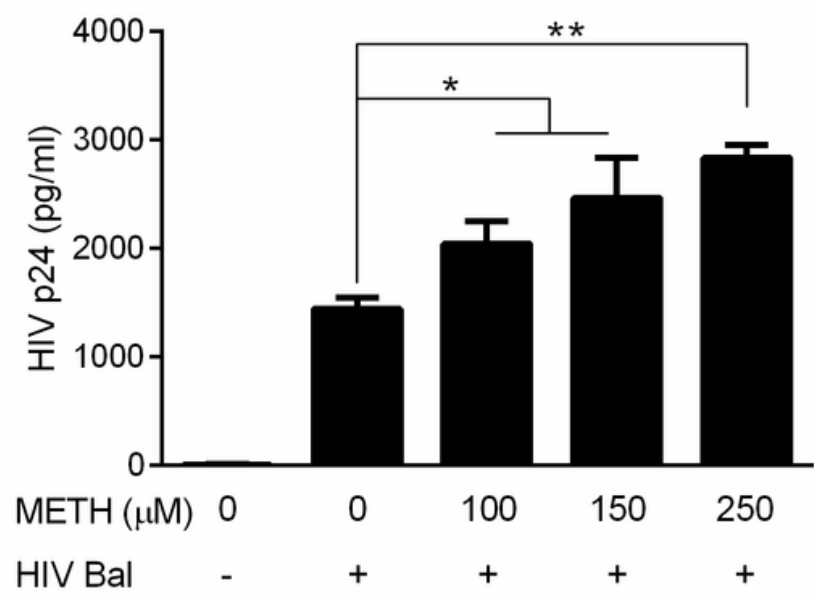

Figure 1

METH enhances HIV infection in vitro. Freshly isolated human monocytes were treated with METH for 24 $h$ and then infected with HIV Bal strain overnight, washed with PBS three times and cultured in the presence of METH for $72 \mathrm{~h}$. RNAs from cells $(\mathrm{A})$ and the cell-free supernatant (B) were extracted and subjected to the real-time PCR using HIV GAG gene primers. (C) Proteins extracted from cells were subjected to Western blot using the antibodies against p24 and GAPDH. (D) The cell-free supernatant 
was subjected to ELISA assay to determine p24 protein level. Data shown were the mean \pm SD from three independent experiments with monocytes from three different donors ( $P<0.05$, ** $P<0.01$ ).
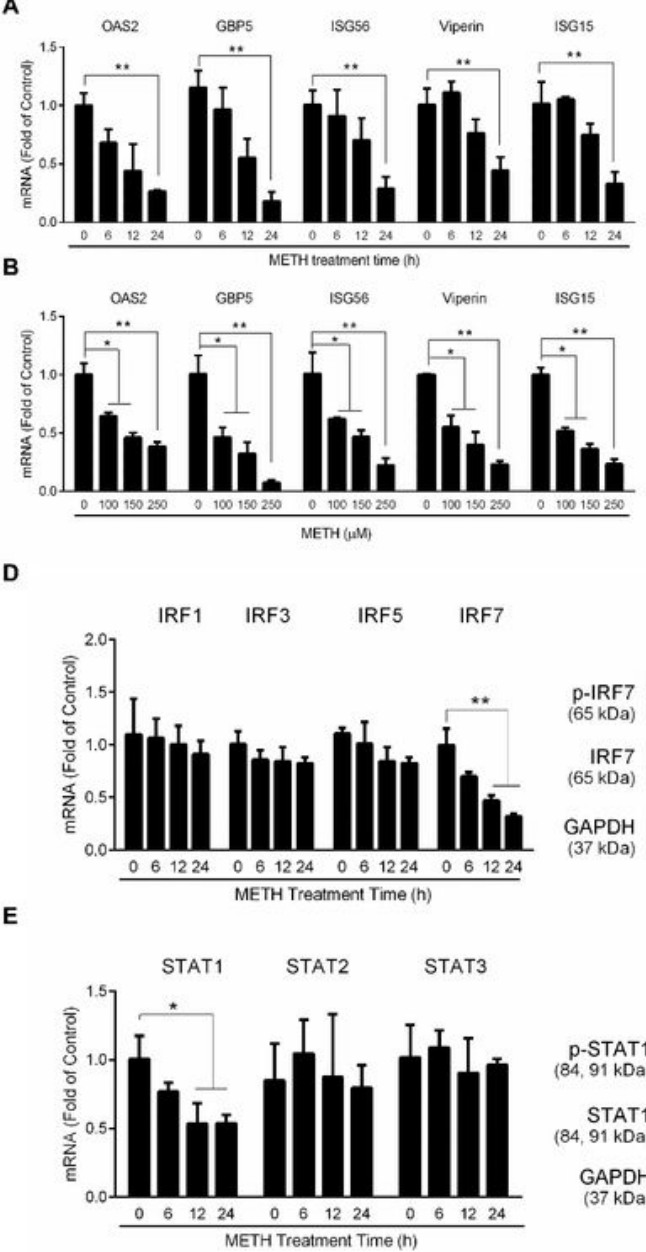

Intracellular (Cells)

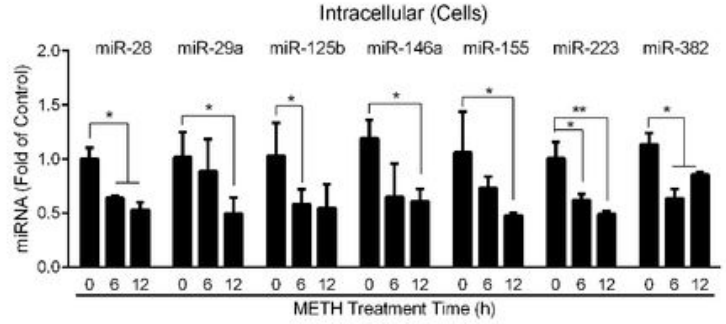

G

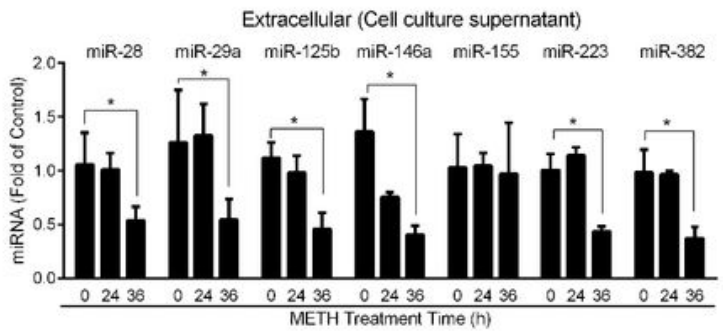

(

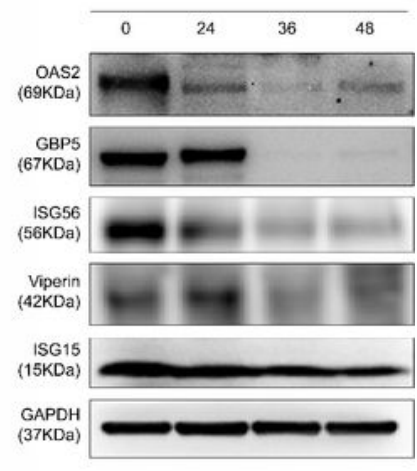

METH Treatment Time (h)
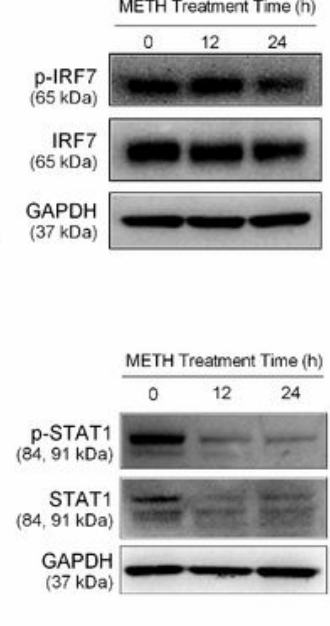
the indicated times, the cellular proteins were then collected and subjected to Western blot assay. ( $D$ and E) The cellular RNAs were extracted and subjected to the real-time PCR to determine the mRNA levels of IRFs and STATs. The cellular proteins were extracted and analyzed with the antibodies against IRF7, pIRF7, STAT1, p-STAT1 and GAPDH. (F) Monocytes were treated with METH at the indicated concentrations for $6 \mathrm{~h}$. Cellular miRNAs were quantified by the real-time PCR. RNU48 was set as a control gene. (G) Monocytes were treated with METH $(150 \mu \mathrm{M})$ for the indicated times. MiRNAs in the culture supernatant were quantified by the real-time PCR. Synthetic caenorhabditis elegans miRNA-39 (cel-miR39) was used as a spiked-in control miRNA for normalization. Data shown were obtained as the mean \pm SD from three independent experiments with monocytes from three different donors $(* P<0.05, * * P<$ $0.01)$.

\section{Supplementary Files}

This is a list of supplementary files associated with this preprint. Click to download.

- SupplemeantalFigure1512021.docx 